\title{
PREDICTIVE VALUE OF TOTAL LEUCOCYTE COUNT (TLC), BILIRUBIN AND C-REACTIVE PROTEIN IN THE DIAGNOSIS OF GANGRENOUS AND PERFORATED APPENDICITIS.
}

\author{
1. MBBS, FCPS \\ Assistant Professor \\ Department of Surgery \\ Sheikh Zayed Medical College \\ Rahim Yar Khan. \\ 2. MBBS, FCPS \\ Assistant Professor \\ Department of SU-III \\ Faisalabad Medical University/ \\ Allied Hospital Faisalabad. \\ 3. MBBS, FCPS \\ Senior Registrar \\ Allied Hospital Faisalabad. \\ 4. MBBS \\ PGR \\ Sheikh Zayed Medical College \\ Rahim Yar Khan. \\ 5. MBBS, FCPS \\ Assistant Professor \\ Allied Hospital, Faisalabad. \\ 6. MBBS, FCPS \\ Senior Registrar \\ Allied Hospital, Faisalabad.
}

Correspondence Address:

Dr. Shahbaz Ahmad Department of SU-III

Faisalabad Medical University/

Allied Hospital Faisalabad.

drshahbaz1076@gmail.com

Article received on:

09/05/2019

Accepted for publication:

23/10/2019
Muhammad Najam Iqbal', Shahbaz Ahmad ${ }^{2}$, Abdullah Saeed $^{3}$, Muhammad Imran Shah ${ }^{4}$, Muhammad Zahid Imtiaz Dogar ${ }^{5}$, Ghulam Mustafa ${ }^{6}$

ABSTRACT: Acute appendicitis is the most common cause of acute abdomen. Most of the cases are diagnosed on history, clinical examination and raised TLC but gangrenous and perforated appendicitis are difficult to diagnose. The TLC, Serum bilirubin and C-reactive protein (CRP) have been shown to indicate perforation in appendicitis. Objectives: The purpose of this study was to evaluate the role of TLC, hyperbilirubinemia and CRP in the diagnosis of perforated appendix and surgery should be planned. Study Design: Prospective study. Setting: Department of Surgery in Sheikh Zayed Medical College Rahim Yar Khan. Period: 12 months from November 2017 to October 2018. Material \& Methods: This study consisted of patients admitted with the clinical suspicion of acute appendicitis. ALVARADO score was calculated. 120 patients with ALVARADO score more than 6 and histologically diagnosed appendicitis were finally included in the study. A proforma was filled which included patients name, age, sex, duration of pain, TLC count, C-Reactive protein (CRP) level and serum total bilirubin level and diagnosis of appendicitis (acute appendicitis, gangrenous appendicitis and perforated appendicitis. Patients were divided into 3 groups. Group A comprised of patients with features of simple appendicitis (AA), Group B Gangrenous appendicitis (GA) and group C Perforated appendicitis (PA). Results: There were 81 patients of acute appendicitis, 13 patients of gangrenous appendicitis and 26 patients of perforated appendicitis. TLC was raised in 13 patients of $A A, 10$ patients of gangrenous appendicitis and 24 patients of perforated appendicitis. Hyperbillirubinemia (>1 mg/dl) was present in 9 patients of GA and 20 patients of PA. Raised C-Reactive protein level (>5mg) was present in 10 patients of GA and 21 patients of PA. There was significant correlation of raised TLC, hyperbillirubinemia and C-reactive protein in gangrenous and perforated appendicitis and $p$ value was less than 0.05 . Predictive value of bilirubin in GA and PA was $56.25 \%$ and $74.04 \%$ respectively. Predictive value of $C$ Reactive Protein in GA and PA was 41.66 and 60 respectively. Predictive value of TLC in GA and PA was 43.47 and 60.86 respectively. Conclusion: All the patients who present with pain in right iliac fossa, lower abdominal tenderness and rigidity, Alvarado score $>7$, raised TLC, CRP and hybillirubinemia are the suspected case of perforated appendix and should be aggressively resuscitated and operated.

Key words: $\quad$ Appendix, C-Reactive Protein, Hyperbilirubinemia, Perforation.

Article Citation: Iqbal MN, Ahmad S, Saeed A, Shah MI, Dogar MZI, Mustafa G. Predictive value of total leucocyte count (TLC), bilirubin and C-reactive protein in the diagnosis of gangrenous and perforated appendicitis. Professional Med J 2019; 26(12):2173-2178. DOI: 10.29309/TPMJ/2019.26.12.3696

\section{INTRODUCTION}

Acute appendicitis is the most common cause of an 'acute abdomen in young adults ${ }^{1}$ and most of the patients present with acute appendicitis between 20 to 40 years. ${ }^{2,3}$ Incidence of acute appendicitis is about $8.6 \%$ in men and $6.7 \%$ women. ${ }^{4}$ Acute uncomplicated appendicitis can be difficult to distinguish clinically from perforated appendicitis, especially in the elderly and in children. ${ }^{2,3}$ The mortality associated with simple acute appendicitis is reported to be $0.3 \%$, but increases to $6 \%$ in cases with perforation. ${ }^{5}$ About $30-50 \%$ cases of Acute Appendicitis are known to have gangrene or perforation at the time of surgery. Only about $35-45 \%$ of patients present in a typical way. So accurate diagnosis and evaluation of severity in most of cases are problematic for surgeon. ${ }^{6}$ Approximately $50 \%$ of cases of gangrenous or perforated appendicitis are associated with a faecolith in contrast with 
uncomplicated appendicitis in which a faecolith is rarely present. ${ }^{7}$ Most of the cases of acute appendicitis are diagnosed by Alvarado score 7 and above. Diagnosis of gangrenous and perforated appendix is challenging. CT scan abdomen can be helpful but it is cost effective and time consuming. Raised TLC, raised level of C-Reactive protein and hyperbillirubinemia can be helpful in making diagnosis of gangrenous/ perforated appendicitis. . $, 9,10,11^{\text {C-reactive protein }}$ (CRP), an acute phase protein, is raised in tissue injury and inflammation and high levels are seen in $A A$ and in gangreneous and perforated appendix, with reported sensitivity as high as $100 \% .{ }^{12,13}$ Severe sepsis results in damage to the hepatocytes and raised serum bilirubin level. ${ }^{14}$ Several studies have found bilirubin to be a useful serological marker for predicting an acute appendicitis. ${ }^{15,16}$ Gangrenous and perforated appendicitis can be predicted with high accuracy by elevated total bilirubin and clinical signs and symptoms. ${ }^{17}$ In our study it is to find out the role of TLC raised c-reactive protein or hyperbillirubinemia in the diagnosis of gangrenous and perforated appendicitis.

\section{MATERIALS AND METHODS}

This prospective study was carried out in Department of Surgery in Sheikh Zayed Medical College Rahim Yar Khan over a period of 12 months from November 2017 to October 2018. This study consisted of 135 patients admitted with the clinical suspicion of acute appendicitis. Finally 120 patients were included in the study who ALVARADO score 7 and above and appendicitis confirmed by histopathology. Detailed history and physical examination was done laboratory tests were advised. A Proforma was filled which included patients name, age, sex, duration of pain in right iliac fossa/lower abdomen, TLC (Total Leukocyte Count), C-Reactive protein (CRP) level and serum total bilirubin level (STB) and diagnosis of acute appendicitis (AA), gangrenous appendicitis (GA) and perforated appendicitis (PA). Normal value of TLC, CRP and STB were taken as $12,000 / \mu \mathrm{L}, 5 \mathrm{mg} / \mathrm{ml}$ and $1.0 \mu \mathrm{mol} / \mathrm{L}$. All the patients underwent open appendicectomy thru grid iron incision. The operative findings were categorised as acute appendicitis, gangrenous or perforated Appendicitis based on the presence of gangrene and perforation. Serological values for these selected variables were compared for acute Appendicitis, gangrenous or perforated to see if there was a significant difference between the groups. Patients undergoing interval appendectomies and patient with negative appendectomies confirmed on histological report were excluded from the study. Other exclusion criteria were patients with risk factors for hepatic disease such as alcoholism, a history of viral hepatitis, Gilbert's disease, hemolytic or liver diseases associated with hyperbilirubinemia.

\section{RESULTS}

Patients aged 15 to above 51 years were included in the study. Most of the patients were between 21- 40 years. Mean age was 25.03. There were $76(63.3 \%)$ male and $44(36.7 \%)$ female. Male to female ratio was 1.68:1 on the basis of operative findings and histopathology, patients were divided into 3 groups. Group A comprised of patients with features of simple appendicitis (AA), Group B Gangrenous appendicitis and group C Perforated appendicitis (GA). There were 47 male and 34 females in group A, 9 male and 5 female in group $\mathrm{C}$ and 20 male and 6 female in group $\mathrm{C}$. Patients were divided into five groups according to age. As shown in Table-I.

All the patients presented with pain abdomen mostly in right iliac fossa but some in lower abdomen. Patients were divided in 2 groups on the basis of duration of pain (duration more than 48 hours and less than 48 hours) as shown in Table-Il.

All the patients who were suspected as a case of acute appendicitis were advised serum bilirubin, CRP (C - Reactive protein) and TLC (Total Leukocytes Count). Serum bilirubin was significantly raised in patients of perforated and gangrenous appendicitis. Hyperbillirubinemia was positive in 7 pateints of simple acute appendicitis (8.6\%), 9 patients of gangrenous appendicitis and 20 patients of perforated appendicitis. Positive predictive of hyperbillirubinemia was 74.07 $\%$ and $56.25 \%$ in perforated and gangrenous appendicitis respectively as shown in Table-III. 
AA: Acute Appendicitis, GA: Gangrenous Appendicitis and PA: Perforated Appendicitis CRP value was raised in 14(17.28\%) patients of simple acute appendicitis but it was significantly raised in both gangrenous and perforated appendicitis with $p$ value less than.05. Positive predictive value of CRP was $41.66 \%$ and $60 \%$ in gangrenous and perforated appendicitis respectively as shown in Table-IV.
TLC was in raised 13 (16.04\%) patients of simple acute appendicitis but it was raised significantly in both gangrenous and perforated appendicitis with $p$ value less than .05 . Positive predictive value of TLC was $43.47 \%$ and $60.86 \%$ in gangrenous and perforated appendicitis respectively as shown in Table-V.

\begin{tabular}{|c|c|c|c|c|c|c|c|}
\hline & Age in Years & Male & \%Age & Female & \%Age & Total & $\%$ Age \\
\hline 1 & $15-20$ & 18 & 15 & 12 & 10 & 30 & 25 \\
\hline 2 & $21-30$ & 21 & 17.5 & 14 & 11.7 & 35 & 29.2 \\
\hline 4 & $41-50$ & 9 & 7.5 & 6 & 5 & 15 & 12.5 \\
\hline 5 & $>50$ & 6 & 5 & 4 & 3.3 & 10 & 8.3 \\
\hline \multicolumn{8}{|c|}{ Table-I. Age and sex distribution } \\
\hline & Duration of Pain & Male & $\%$ Age & Female & \%Age & Total & $\%$ Age \\
\hline 1 & $<48$ hours & 43 & $35.8 \%$ & 28 & $23.3 \%$ & 71 & $59.1 \%$ \\
\hline 2 & $>48$ hours & 33 & $27.6 \%$ & 16 & $13.3 \%$ & 49 & $40.9 \%$ \\
\hline
\end{tabular}

\begin{tabular}{|c|c|c|c|c|c|c|c|}
\hline & $\begin{array}{c}\text { Billirubin } \\
>1.0 m g\end{array}$ & $\begin{array}{c}\text { Bilirubin } \\
<1.0 m g\end{array}$ & \%Age & Sensitivity & Specificity & $\begin{array}{c}\text { Positive } \\
\text { predictive Value }\end{array}$ \\
\hline GA & 9 & 4 & $69.23 \%$ & $69.23 \%$ & $91.35 \%$ & $56.25 \%$ \\
\hline PA & 20 & 6 & 76.96 & 76.96 & 91.35 & $74.07 \%$ \\
\hline
\end{tabular}

Table-III. Serum billirubin level statistics

\begin{tabular}{|c|c|c|c|c|c|}
\hline & CRP $>5$ & CRP $<5$ & Sensitivity & Specificity & $\begin{array}{c}\text { Positive Predictive } \\
\text { Value }\end{array}$ \\
\hline $\begin{array}{c}\text { Gangrenous } \\
\text { Appendicitis }\end{array}$ & 10 & 3 & $76.92 \%$ & $82.71 \%$ & $41.66 \%$ \\
\hline $\begin{array}{c}\text { Perforated } \\
\text { Appendicitis }\end{array}$ & 21 & 5 & $80.76 \%$ & $82.71 \%$ & 0.000 \\
\hline
\end{tabular}

Table-IV. CRP Level Statistics

\begin{tabular}{|c|c|c|c|c|c|c|}
\hline & $\begin{array}{c}\text { TLC } \\
>12000\end{array}$ & TLC<12000 & Percentage & Sensitivity & Specificity & $\begin{array}{c}\text { Positive Predictive } \\
\text { Value }\end{array}$ \\
\hline GR & 10 & 3 & $76.92 \%$ & 76.92 & 83.95 & 43.47 \\
\hline PA & 24 & 2 & $92.30 \%$ & 92.30 & 83.95 & 64.86 \\
\hline
\end{tabular}

\section{DISCUSSION}

Appendicitis is one of the major surgical presentation in the emergency settings and diagnosis is usually clinical and there are a number of diagnostic scoring systems that direct toward the exact prediction regarding its diagnosis. Different laboratory data, ultrasonography and CT scan of the abdomen are very helpful. However, the clinical assessment to predict the perforated and gangrenous one is lacking and there are a 
number of attempts made to predict it precisely for early anticipation before going to surgery. ${ }^{18-20}$

Hyperbilirubinemia is considered as one of the important parameter to predict perforation or gangrenous nature of appendix. There are a number of causes that can lead to hyperbilirubinemia. Bacteria are removed by the detoxification and immunological action of reticuloendothelial system of the liver that acts as first-line defence but due to excessive load of bacteria in cases of perforated and gangrenous appendicitis, Kupffer cell function get saturated and lead to liver cells dysfunction and lead a rise in serum bilirubin (SB) alone or in combination with liver enzymes depending upon the type, severity and site of the lesion. The association between the elevated SB levels and the variety of infectious diseases has been noted in different studies. ${ }^{21,22}$

In the present study hyperbilirubinemia was seen in 20 (76.96\%) patients of the perforated appendicitis, $9(64.28 \%)$ patients of gangrenous appendicitis, 7 (8.6\%) patients of simple acute appendicitis and the sensitivity, specificity and positive predictive value were $76.96 \%$, $91.35 \%$ and $74.07 \%$ respectively in perforated appendicitis with P-Value less than .05 and the sensitivity, specificity and positive predictive value in gangrenous appendicitis were $69.23 \%$, $91.35 \%$ and $56.25 \%$ respectively with $p$ value less than .05. This finding was similar to the studies done in the past. According to a study done by Jamaluddin $\mathrm{M}$ et al in cases with perforated appendices, the serum bilirubin of $1 \mathrm{mg} / \mathrm{dl}$ or more was seen in $57.7 \%$ of cases. ${ }^{23}$

While in another study done by Atahan $\mathrm{K}$ et al the bilirubin level of more than $1 \mathrm{mg} / \mathrm{dl}$ was seen in $80 \%$ of the cases with complicated appendicitis (gangrenous and perforated). ${ }^{24}$ According to a similar study done by Eren $\mathrm{T}$ et al raised bilirubin was seen in $10 \%$ cases with simple appendicitis and $59 \%$ with perforated/ gangrenous one. ${ }^{25}$

According to a study done by Cheekuri et al, they compared the three groups i.e. normal cases, acute appendicitis and the cases with perforated/ gangrenous appendicitis. According to this study bilirubin more than $1 \mathrm{mg} / \mathrm{dl}$ was seen in 2 (3.4\%), 25 (43.2\%) and 31 (53.4\%) of cases respectively with $p$ value less than 0.05 and over all sensitivity of $94 \$$, specificity of $66.66 \%$, PPV of $88.5 \%$ and NPV of $80 \%{ }^{26}$ In another study by Estrada et al odd ration see for association of hyperbilirubinemia with perforated appendicitis was seen as 2.96 $(95 \% \mathrm{Cl}, 1.11-7.6)$ with $p$ value of $0.031 .^{27}$

According to a retrospective analysis done by Emmanuel et al in 2011 found that hyper bilirubinemia was significantly high in cases that presented with mean longer duration of time with $p$ value of 0.001 and specificity was seen in $88 \%$ of the cases. ${ }^{28}$

The second parameter we studied was CRP. CRP levels increase between 8-12 hours after the onset of inflammatory process and peak around 24 and 48 hours. Consequently, it is a strong predictor of complicated appendicitis. In our study raised level of CRP in acute appendicitis, gangrenous appendicitis and perforated appendicitis was seen in $14(17.2 \%), 10$ (76.92\%) and $21(80.76 \%)$ patients respectively. Sensitivity, specificity and positive predictive value were $76.92 \%$, $82.71 \%$ and $41.66 \%$ in gangrenous appendicitis and $80.76 \%, 82.71 \%$ and $60 \%$ in perforated appendicitis respectively. S. Yokoyama et al established that CRP $>5 \mathrm{mg} / \mathrm{dl}$ is an independent indication of surgery in AA, with a sensitivity of $84.3 \%$, specificity of $75.8 \%$, positive predictive value of $64.2 \%$ and NPV of $90.4 \%$ for identifying complicated appendicitis. They found that the CRP levels were significantly higher $(4.09 \pm 4.33$ $\mathrm{mg} / \mathrm{dl}$ vs $11.47 \pm 7.59 \mathrm{mg} / \mathrm{dl}, \quad \mathrm{p}<0.0001)$ in patients with perforated appendicitis, needing early surgical intervention. ${ }^{29}$ H.M. Moon found sensitivity of CRP for identifying complicated appendicitis was $57.6 \%$; specificity, $98.3 \%$, the positive predictive value $97.4 \%$, and the negative predictive value was $68.5 \% .{ }^{30}$ These values in $\mathrm{W}$. Farooqi's study were 54\%, 79\%, 49\% and $82 \%$. Studies have shown sensitivity of CRP as high as $98 \%$ for identifying perforation in appendicitis. ${ }^{15}$

TLC, C Reactive protein and hyperbillirubinemia are considered as diagnostic aid in complicated appendicitis. In our study, raised TLC (>12000) 
was found in 13 (16\%) in acute appendicitis, $10(76.92)$ in gangrenous appendicitis and 24 (92.30\%) in perforated appendicitis. In their study Mcgowan et al. they found that the biochemical markers (bilirubin, CRP and white cell count were significantly higher in perforation $(P<0.001)$. The greatest sum of sensitivity and specificity of CRP at $34.6 \mathrm{mg} / \mathrm{l}$ (sensitivity $78.57 \%$, specificity $63.01 \%$, and bilirubin was at $21.5 \mu \mathrm{mol} / \mathrm{L}$ (sensitivity $62.96 \%$, specificity (88.31\%). They concluded that Bilirubin and CRP are markers of perforation in appendicitis, but are not accurate enough to be diagnostic. ${ }^{31}$ Andrew Emmanuel established hyperbilirubi-naemia as a strong predictor of acute appendicitis, ${ }^{25}$ and found that it is more specific compared to TLC and CRP for identifying patients with perforation or gangrene, (respective specificity 701936$).^{28}$

\section{CONCLUSION}

All the patients who present with pain in right iliac fossa, lower abdominal tenderness and rigidity, Alvarado score $>7$, raised TLC, CRP and hybillirubinemia are the suspected case of perforated appendix and should be aggressively resuscitated and operated.

\section{Copyright@ 23 Oct, 2019.}

\section{REFERRENCES}

1. William Norman S, J.K. Bulstrode Christopher and O'Connel P. Ronan. The Vermiform Appendix: Bailey and love's short practice of surgery. $27^{\text {th }}$ edition. 2018; 1299-1300.

2. Konan A, Hayran M, Kılıç YA, Karakoç D, Kaynaroğlu V. Scoring systems in the diagnosis of acute appendicitis in the elderly. Ulus Travma Acil Cerrahi Derg 2011; 17:396-400.

3. Escribá A, Gamell AM, Fernández Y, Quintillá JM, Cubells CL. Prospective validation of two systems of classification for the diagnosis of acute appendicitis. Pediatr Emerg Care 2011; 27:165-9.

4. G.Y. Stein, L. Rath-Wolfson, A. Zeidman. Sex differences in the epidemiology, easonal variation, and trends in the management of patients with acute appendicitis. Langenbeck's Arch Surg. 2012 Oct; 397(7):1087-92

5. Sand M, Bechara FG, Holland-Letz T, Sand D, Mehnert G, Mann B. Diagnostic value of hyperbilirubinemia as a predictive factor for appendiceal perforation in acute appendicitis. Am J Surg 2009; 198:193-8.
6. R. Sleem, S. Fisher. Perforated appendicitis: Is early laparoscopic appendectomy appropriate? Surgery 2009; 146(4)731

7. Cuschieri Alfred, B Hanna George. The vermiform appendix: Essential Surgical Practice. $5^{\text {th }}$ edition. 2015; 926-927.

8. Muhammad Waseem Anwar, IrumAbid. Validity of total leucocytes count and neutrophil count (differential leucocytes count) in diagnosing suspected acute appendicitis. Sep 2012(3):

9. W. Farooqui, H-C. Pommergaard, J. Burcharth. The diagnostic value of a panel of serological markersin acute appendicitis. Scandinavian Journal of Surgery 0: 1-7, 2014.

10. Ahan,1 O Üreyen,1 E Aslan,1 M Deniz,1 A. Preoperative diagnostic role of hyperbilirubinaemia as a marker of appendix perforation. J Intl Med Research, 2011; 39: $609-618$

11. Ahmad Q.A, Muneera M.J, Rasool.M.I. Predictive value of TLC and CRP in the diagnosis of acute appendicitis. ANNALS. APR-JUN 2010; 16:116-9.

12. Shozo Yokohama et al. C Reactive protein is an independent surgical indication marker for appendicitis: A retrospective study. W J Emerg Surg. 2009 Oct. 4;36

13. The value of Hyperbilirubinemia in the diagnosis of acute appendicitis. Annals Royal College of Surgeons England 2011 April 93(3):213-7.

14. M Jamaluddin, S M AHussein. Hyperbilirubinaemia a predictive factor for complicated acute appendicitis: A study in a tertiary care hospital. JPMA 2013, 11.63 1374.

15. McGowan DR, Sims HM, Shaikh I, Uheba M. The value of hyperbilirubinaemia in the diagnosis of acute appendicitis. Ann R Coll Surg Engl 2011; 93:498.

16. Emmanuel A, Murchan P, Wilson I, Balfe P. The value of hyperbilirubinaemia in the diagnosis of acute appendicitis. Ann R Coll Surg Engl 2011; 93:213-7.

17. Garst GC1, Moore EE, Banerjee MN, Leopold DK. Acute appendicitis: $A$ disease severity score for the acute care surgeon. J Trauma Acute Care Surg. 2013 Jan; 74(1):32-6

18. Seal A. Appendicitis: A historical review. Can J Surg. 1981; 24:427-433. 
19. Amyand $\mathrm{C}$. Of an inguinal rupture, with a pin in the appendix caeci encrusted with stone: Some observations on wounds in the guts. Philos Trans $R$ Soc Lond. 1736; 39:329-336.

20. Franke C, Bohner H, Yang Q, Ohmann C, Roher HD Acute Abdominal Pain Study Group. Ultrasonography for diagnosis of acute appendicitis: Results of a prospective multicenter trial. World J Surg. 1999; 23:141-146.

21. Poortman P, Lohle PN, Schoemaker CM, Oostvogel HJ, Teepen HJ, Zwinderman KA, et al. Comparison of CT and sonography in the diagnosis of acute appendicitis: A blinded prospective study. AJR Am J Roentgenol. 2003; 181:1355-1359.

22. Cakirer S, Basak M, Colakoglu B, Bankaoglu M. Diagnosis of acute appendicitis with unenhanced helical CT: A study of 130 patients. Emerg Radiol. 2002; 9:155-161.

23. Jamaluddin $M$, Hussain SMA, Ahmad $H$. Hyperbilirubinemia a predictive factor for complicated acute appendicitis: A study in a tertiary care hospital. J Pak Med Assoc. 2013; 63(11):1374-78.

24. Atahan K, Ureyen O, Aslan E, Deniz M, Cokmez A, Gur S, et al. Preoperative diagnostic role of hyperbilirubinaemia as a marker of appendix perforation. J Int Med Res. 2011; 39:609-18.
25. Eren T, Tombalak E, Ozemir IA, Leblebici M, Ziyade S, Ekinci $O$, et al. Hyperbilirubinemia as a predictive factor in acute appendicitis. Eur $\mathrm{J}$ Trauma Emerg Surg. 2016; 42(4):471-76.

26. Cheekuri SK, Mohanty A, Ganesh T, Kannan R, Smile R. Hyperbilirubinemia as a predictor of the severity of acute appendicitis - an observational study. Int Surg J 2017; 4:1341-4.

27. Estrada,JJ, M. Petrosyan, J. Barnhart, M. Tao, H. Sohn, S. Towfigh, et al. Hyperbilirubinemia in appendicitis: A new predictor of perforation. $J$ Gastrointest Surg, 11 (6) (2007 Jun), 714-718

28. Emmanuel A, P. Murchan, I. Wilson, P. Balfe The value of hyperbilirubinaemia in the diagnosis of acute appendicitis. Ann R Coll Surg Engl, 93 (3) (2011), pp. 213-217

29. Alnjadat I, Abdallah B. Alvarado versus RIPASA score in diagnosing acute appendicitis. Rawal Medical Journal. 2013;38(2):147-51.

30. Nicolaj Duus, Nicolaj Deus Diagnosing Appendicitis: Evidence-Based review of the diagnostic approach in 2014. The western journal of emergency medicine $11 / 2014 ; 15(7): 859-871$

31. McGowan DR, Sims HM, Zia K, Uheba M, Shaikh IA. The value of biochemical markers in predicting a perforation in acute appendicitis. ANZ J Surg 2013; 83:79-83.

\begin{tabular}{|c|c|c|c|}
\hline \multicolumn{4}{|c|}{ AUTHORSHIP AND CONTRIBUTION DECLARATION } \\
\hline Sr. \# & Author(s) Full Name & Contribution to the paper & Author(s) Signature \\
\hline 1 & Muhammad Najam Iqbal & Principal investigator & \\
\hline 2 & Shahbaz Ahmad & Manuscript writing & \\
\hline 3 & Abdullah Saeed & Manuscript writing & \\
\hline 4 & Muhammad Imran Shah & Data collection & \\
\hline 5 & M. Zahid Imtiaz Dogar & Data collection & \\
\hline 6 & Ghulam Mustafa & $\begin{array}{l}\text { Reference writing \& Proof } \\
\text { reading. }\end{array}$ & \\
\hline
\end{tabular}

